\section{Fracture Resistance of Full Ceramic Primary Crowns}

\section{LaQuia A Vinson ${ }^{1 *}$, Carter M McCrea ${ }^{1}$, Jeffrey A Platt ${ }^{2}$, Brian J Sanders ${ }^{1}$, James $E$ Jones $^{1}$ and James A Weddell ${ }^{1}$}

'Department of Pediatric Dentistry, James Whitcomb Riley Hospital for Children, Indiana University School of Dentistry, Indiana University, Indianapolis, Indiana, USA

${ }^{2}$ Department of Biomedical and Applied Sciences, Indiana University School of Dentistry, Indiana University, Indianapolis, Indiana, USA

\begin{abstract}
Purpose

The purpose of this study was to determine the maximum occlusal load to failure for an ESSC (NuSmile) and 2 types of primary full ceramic crowns (Kinder Krown and EZ Pedo) and compare these loads with previously reported posterior occlusal forces.

Methods

Negative replicas of each company's crown were fabricated with polyvinyl siloxane impression material, allowed to set for 24 hours and used to fabricate epoxy dies for each crown. The crowns were cemented to the epoxy dies with glass ionomer cement. The die-crown units were fractured using a universal testing machine with a stainless steel ball fixture, set in a uniaxial lever. The 3 types of crowns were compared by means of a one-way analysis of variance. Pair wise comparisons were performed with Fisher's protected least significant differences.

Results
\end{abstract}

Kinder Krown crowns had a significantly lower force required to fracture than the EZ Pedo and NuSmile crowns. The force to fracture the EZ Pedo and NuSmile crowns was not significantly different between these two.

\section{Conclusion}

The three types of crowns tested withstood the application of uniaxial forces greater than the reference values for posterior occlusal loads.

Keywords: Dental crown; Dental esthetics; Dental restoration; Pediatric dentistry

\section{Introduction}

Early childhood caries remains a significant problem challenging the preventive and restorative skills of the dental field [1]. In addition,

\footnotetext{
*Corresponding author: LaQuia A Vinson, Department of Pediatric Dentistry, Indiana University School of Dentistry, Indiana University, 705 Riley Hospital Dr, Indianapolis, IN 46202, USA, Tel: +1 3179480886; E-mail: laqawalk@iu.edu
}

Citation: Vinson LA, McCrea MC, Platt JA, Sanders BJ, Jones JE, et al. (2016) Fracture Resistance of Full Ceramic Primary Crowns. J Dent Oral Health Cosmesis 1: 005.

Received: March 21, 2016; Accepted: May 04, 2016; Published: May 18, 2016 the prevalence of caries among children 2-11 years of age has been increasing [2]. There are several options from which to choose when restoring primary teeth: these include restorations such as amalgam, Stainless Steel Crowns (SSC), resin, glass ionomer, Esthetic Stainless Steel Crowns (ESSC) and full ceramic primary crowns [3-5]. Esthetic considerations have been shown to be very important to the consumer, and further research is necessary to develop reliable, more visually pleasing restorations that fulfill this need [6-7].

The demand for the use of esthetic restorations continues to increase in pediatric dentistry [8]. With parents being more involved in clinical decision-making than ever before, many have greater expectations for dentists' to improve the appearance of their child's decayed dentition [2]. Reports show that "from a purely cosmetic standpoint, the value of the appearance of one's teeth is important in Western society. The public places an increasing priority on an attractive smile" [9]. When it comes to their children's dental care, parents typically apply their own esthetic expectations. When operative treatment is warranted, parents' preferences often favor whichever restoration is more esthetically pleasing [8]. Previous reports demonstrated longevity to be preferred over esthetics among dental clinicians, while parents and adolescent patients favor appearance [6]. Zimmerman found that out of 301 pediatric dentists surveyed, pressure from parents to place tooth-colored restorations was reported "sometimes" (66\%), "often" (3\%), and "never" (32\%) and to place 2-surface restorations rather than SSCs "sometimes" (69\%), "often" (8\%), and "never" (23\%) [8].

The American Academy of Pediatric Dentistry (AAPD) advocates the use of a full coverage restoration for "children with extensive decay, large lesions, or multi-surface lesions in primary molars [5]. The most often used and recommended restoration has been the Stainless Steel Crown (SSC) [2]. SSCs are very effective and durable restorations for primary molars [10]. They are the restoration of choice for pediatric dentition with caries, cervical decalcification, and/or developmental defects when other available restorative materials are likely to fail. They are also the recommended restoration following pulpotomy or pulpectomy treatment of posterior primary teeth $[5,11]$. Previous research supports evidence of enhanced clinical success over time, in terms of better retention and less recurrent decay, with SSCs versus composite resin and amalgam Class II restorations with multi-surface carious lesions $[2,12]$. Recent studies have indicated a range of $1.9 \%-12 \%$ rate of failure due to perforations or dents of over a 2 to 7 year period $[12,13]$. Stainless steel crowns are durable, easy to place, retentive and require minimal chair time. However, one drawback is that they are unaesthetic which can discourage parents and practitioners away from their use [3].

The use of ESSCs and full ceramic primary crowns now allow dentists to provide a durable and esthetic restoration when full coverage is necessary [4]. The ESSC was introduced to dentistry in the mid-1990s [14]. Initially developed for primary anterior teeth, ESSCs are now available for all primary dentition [4]. The restoration is a traditional stainless steel crown with mechanically or chemically bonded esthetic material (usually composite or porcelain) covering one or more surfaces of the crown. The composite or porcelain aspects 

005 .

are available in various shades capable of matching most dentitions and can adequately hide the metallic appearance of the base metallic structure. To do so, these esthetic materials must be applied at a thickness of 1.5 to 2 millimeters in order to properly withstand the patient's occlusal forces [2]. When these materials are combined with a SSC, the stainless steel acts as a thin yet strong foundation for the composite or porcelain. ESSCs are easy to place; less affected by saliva or gingival hemorrhage, and require minimal working time.

Primary full ceramic crowns are the most recent restorative products to be introduced to the dental market. These metal-free pediatric restorations are milled from monolithic zirconia, developed for both anterior and posterior primary dentition, are autoclavable and available in multiple sizes. Zirconia ceramics have been utilized in dentistry for adult indirect restorations for over 15 years because of their high strength, wear resistance, durability, biocompatibility and esthetic properties [15]. The highest average thickness of the pediatric full ceramic crown is approximately $0.5-0.73 \mathrm{~mm}$ making the occlusal preparation similar to that for the standard SSC $[16,17]$.

Although superior in appearance, ESSCs and full ceramic crowns require several modifications from the traditional SSC preparation. Aesthetic stainless steel crowns require more reduction and subsequently a greater loss of tooth structure [2]. This can result in a greater chance of post-operative sensitivity or mechanical exposure of the pulp. A risk associated with these crowns is the inability to absorb appreciable quantities of plastic strain energy prior to fracture. If excessive force is placed on the crown during seating, the restoration has the potential to break [16]. Problems also exist with contouring and/or crimping these crowns. Attempts to alter the shape of the ESSCs with moderate crimping may actually reduce crown retention and/or cause damage to or loss of the esthetic facing [1]. This breakage can occur while in the chair or weeks following cementation, leading to increased plaque retention and space-loss in the developing dentition [2]. Full ceramic crowns are unable to be crimped for adaptive purposes, thus forcing these restorations to rely more heavily on the bond of the cement for retention instead of the additional mechanical lock obtained from crimping stainless steel crowns [5,16]. Occlusal and interproximal adjustments are not recommended because it will remove the crown's glaze and create weak areas and perforations within the ceramic [5]. In an article by Roberts, $54 \%$ of esthetic posterior crowns placed resulted in negative outcomes involving the esthetic aspect of the crown. This included complete loss of the aesthetic facing, fracture, chipping, wear and discoloration after a two year period [1]. Yimalz found that after four years, $100 \%$ of esthetic crowns tested showed chipping of the esthetic materials. Repair of esthetic surface failures is possible with the use of materials like composite resin, however the only way to restore the restoration to its original luster would be to replace the crown [14].

The first primary molars are the primary teeth that most commonly receive full-coverage restorations [11]. The maximum bite force in the area of the first primary molar and the first permanent premolar was measured by Braun and colleagues. Linear regression generated values of maximum bite force ranging from 78 Newton's $(\mathrm{N})$ for 6 year-olds to $106 \mathrm{~N}$ for 10 year-olds [18]. The purpose of this study was to determine the maximum occlusal load to failure for an ESSC and two types of full ceramic primary crowns with the comparison of these loads to the posterior occlusal forces reported by Braun and colleagues in the primary first molar area of patients 6 to 10 years of age $(78-106 \mathrm{~N})$.

\section{Materials and Methods}

The force required to fracture the esthetic element of 3 types of esthetic crowns for primary mandibular first molars was measured [18]. Testing was conducted on two types of full ceramic crowns (manufactured by 2 companies: EZ Pedo Crowns, EZ Pedo, Inc. Loomis, CA; Kinder Krowns, St. Louis Park, MN) and 1 ESSC (manufactured by NuSmile Primary Crowns, Houston, TX). Twenty-five specimens of primary mandibular left first molars from each company were tested.

A negative replica of each company's crown was fabricated with polyvinyl siloxane impression material (Examix NDS, GC Corporation, Tokyo, Japan) and allowed to set for 24 hours. These impressions were then used to fabricate idealized epoxy dies (Gorilla Glue Epoxy, Gorilla Glue, Inc, Cincinnati, OH) for each crown which were allowed to set for 1 week. The crowns and dies were tried on to ensure a passive fit. Any visible undercuts on the dies were removed. The esthetic crowns were then cemented on to the epoxy dies according to the manufacturer's instructions with Glass Ionomer (GI) cement (Ketac Cem, 3M ESPE). This was done by cleaning the die with dry gauze and air, activating the GI capsule for 3 seconds, mixing the capsule for 10 seconds, lining the inside of the crown with cement, placing the crown and holding it in place for 5 seconds. The die-crown units were then allowed to set for 24 hours on the bench top.

Each die-crown unit was placed into a universal Mechanical Testing Machine (MTS, Eden Prairie, MN) (Figure 1) and loading increased until the crowns fractured (Figure 2).

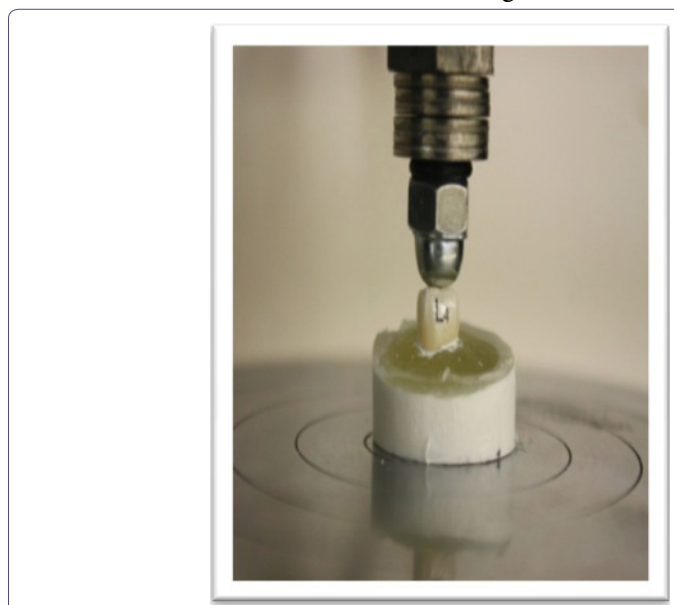

Figure 1: Die-crown unit placed in a universal mechanical testing machine.

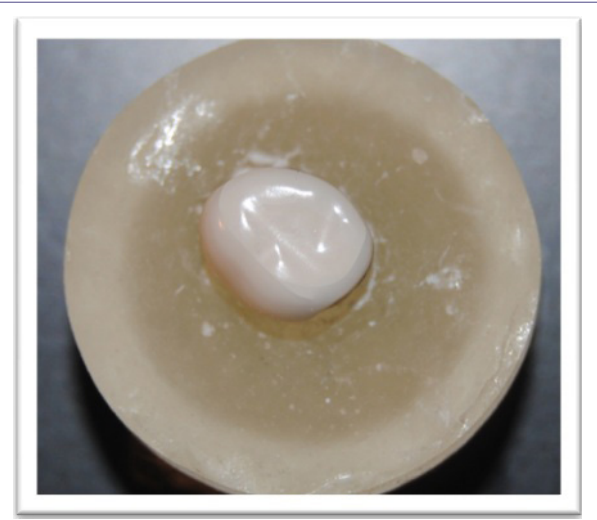

Figure 2: Crown fractured after loading 

005 .

Fractures were determined through audio and mechanical detection during loading. Verification that failure occurred in the ceramic crown after audio detection was completed visually or stereo microscopically, as needed. The force was delivered through a stainless steel ball fixture of $6.35 \mathrm{~mm}$ in diameter set in a uniaxial lever intended to replicate a 3 -point contact. Testing was performed in 1 cycle, with the speed of the crosshead maintained at $1 \mathrm{~mm} / \mathrm{min}$, until the esthetic component fractured. The unit of measurement for this study was Newton's (N). Post failure analysis included the use of methylene blue dye to detect esthetic failures difficult to assess visually.

Based on prior study results, the with in-group standard deviation of the force required to fracture was estimated to be $330 \mathrm{~N}$ [2]. With a sample size of 25 crowns per group, the study was designed to have $80 \%$ power to detect a difference of $267 \mathrm{~N}$ between any 2 groups, assuming a 2 -sided $5 \%$ significance level for each test.

The 3 types of crowns were compared for differences in the force required to fracture using 1-way Anova. Pair-wise comparisons were performed using fisher's protected least significant differences to control the overall significance level at 5\%. Confidence intervals around the mean were calculated and compared with the reference value of 78-106 $\mathrm{N}$ for posterior occlusal loads, as reported previously by Braun and colleagues.

\section{Results}

Twenty-five specimens were included within each of the three groups (EZ Pedo, Kinder Krowns, NuSmile). Summary statistics are presented in Table 1.

\begin{tabular}{|c|c|c|c|c|c|}
\hline Group & N & Min & Max & Mean (SE) & $\begin{array}{c}\text { 95\% Cl for } \\
\text { Mean }\end{array}$ \\
\hline EZ Pedo (full ceramic) & 25 & 710.69 & 1807.54 & $1099(58) *$ & 980 to 1218 \\
\hline $\begin{array}{c}\text { Kinder Krowns (full } \\
\text { ceramic) }\end{array}$ & 25 & 338.7 & 1168.74 & $705(45)$ & 611 to 798 \\
\hline NuSmile (ESSC) & 25 & 542.34 & 1982.2 & $1214(82) *$ & 1045 to 1382 \\
\hline $\begin{array}{c}\text { * Statistically similar } \\
\text { groups }\end{array}$ & & & & & \\
\hline
\end{tabular}

Table 1: Force required to fracture esthetic primary posterior crowns.

Kinder Krowns had significantly lower force required to fracture than EZ Pedo $(\mathrm{p}<0.0001)$ and NuSmile $(\mathrm{p}<0.0001)$, while EZ Pedo and NuSmile were not significantly different $(\mathrm{p}=0.20)$ (Figure 3 ).

\section{Mean (SE) Occlusal Load To Failure}

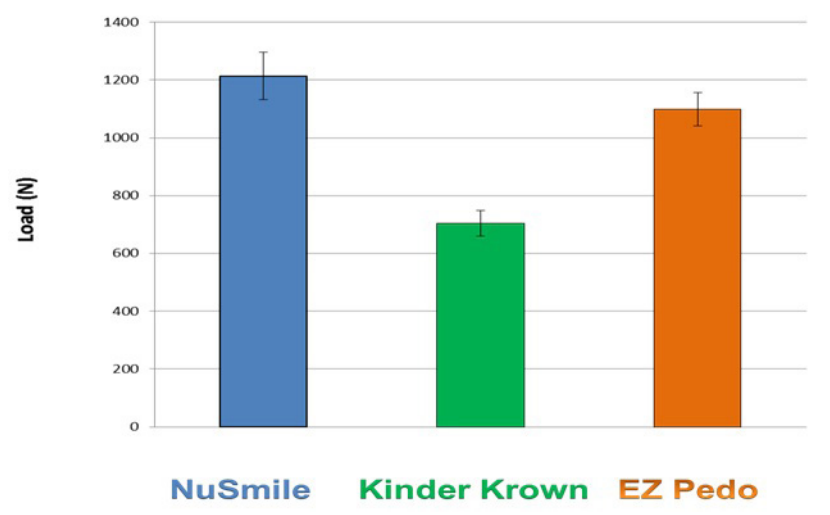

Figure 3: Mean occlusal load to failure with $95 \% \mathrm{Cl}$.
All confidence intervals and force ranges were found to be greater than the reference values for posterior occlusal loads documented by Braun and colleagues.

\section{Discussion}

The purpose of this project was to determine the maximum occlusal load to failure of two types of full ceramic primary posterior crowns and 1 type of ESSC for the purpose of comparing them with the average posterior occlusal forces determined by Braun and colleagues. The mandibular primary first molar region was the area selected for study as it is the area most often requiring full coverage restorations in the primary dentition [11].

The results of this study indicate that all 3 esthetic crowns were able to withstand the occlusal forces of the primary first molar and premolar areas in children when compared to the values determined by Braun [18]. Despite these promising results, in vivo studies suggest otherwise as evident in a study by Roberts, where $54 \%$ of esthetic posterior crowns placed resulted in esthetic failure within 2 years following placement [1]. This can be attributed to multiple elements not represented in this study. First, uniaxial loading alone does not occur in the oral environment. Mastication is represented by cyclical or multiaxial loading, which includes horizontal loading (shearing) as well as vertical (compression) [19]. Second, continuous moisture and chemical variations experienced in the mouth can significantly affect the longevity of restorative materials. The temperature of the oral environment along with the large degree of temperature variations it exhibits can contribute to the deterioration of restorations. Fourth, the consistent stress resulting from daily cyclical mastication forces can weaken restorative materials over time (fatigue). Beginning as small cracks, these areas may grow and eventually lead to fracture and failure. Lastly, epoxy dies were used in this study. As was evident in Townsend's study, custom epoxy dies allowed for a better fit and for a uniform thickness of cement to be used [20]. Extracted teeth were not used because there is greater potential for inconsistent results due to the variance that could be produced from the preparation of extracted teeth. The clinical preparation of a tooth for full coverage restoration is not always ideal and ill-fitting or under supported restorations could result in increased stress within the restorative material and increased likelihood of fracture. As noted in Yucel's study, "there is no significant difference in the fracture strength of dentin and epoxy resin dies" [21].

The mean occlusal loads to failure of the 3 crowns tested in this study were lower than those produced by similar research performed by Beattie and colleagues [2]. Despite the inclusion of monolithic zirconia crowns with in this project, other elements may account for this difference. The Glass Ionomer (GI) cement used in this project lacks the compressive strength possessed by Resin-Modified Glass Ionomer (RMGI) cement used in the previous study. The use of audio detection to determine failure in this study stopped the occlusal load in many samples prior to the mechanical detection of failure by the universal testing device. This allowed for smaller fractures to be detected and recorded as failure prior to catastrophic failure with some samples. With the full ceramic crowns lacking the metal coping possessed by ESSCs, these fractures could lead to bacterial invasion and further decay. The difference in materials and failure detection methods may account for the variance of results between studies.

\section{Conclusion}

Based on this study's results, the following conclusions can be made. All 3 crowns tested were found to withstand the application of 

005 .

uniaxial forces greater than the reference values for posterior occlusal loads documented by Braun and colleagues [18]. The forces determined to cause failure with NuSmile ESSCs and EZ Pedo full ceramic crowns were not significantly different $(\mathrm{p}=0.20)$. Kinder Krowns however did fracture at a significantly lower force.

\section{Acknowledgment}

Support for this project was provided by the Delta Dental Foundation. The authors wish to thank Mr. George Eckert (MAS, Department of Biostatistics, Indiana University School of Medicine) for providing the statistical analysis for this study. Also, Dr. Angela Tomlin (Associate Professor of Clinical Pediatrics, Child Development Center, James Whitcomb Riley Hospital for Children, Indiana University), Ms. Meoghan MacPherson (MS, Indiana University School of Dentistry), and Ms. Lori Mathias (Lab Technician, James Whitcomb Riley Hospital for Children Dental Clinic, Indiana University) for their help in the preparation of the manuscript.

\section{Conflict of Interest}

The authors declare that there are no conflicts of interest.

\section{References}

1. Roberts C, Lee JY, Wright JT (2001) Clinical evaluation of and parental satisfaction with resin-faced stainless steel crowns. Pediatr Dent 23: 28-31.

2. Beattie S, Taskonak B, Jones J, Chin J, Sanders B, et al. (2011) Fracture resistance of 3 types of primary esthetic stainless steel crowns. J Can Dent Assoc 77: 90 .

3. Gupta M, Chen JW, Ontiveros JC (2008) Veneer retention of preveneered primary stainless steel crowns after crimping. J Dent Child (Chic) 75: 44-47.

4. Oueis H, Atwan S, Pajtas B, Casamassimo PS (2010) Use of anterior veneered stainless steel crowns by pediatric dentists. Pediatr Dent 32: 413-416.

5. American Academy of Pediatric Dentistry Reference Manual 2015-2016. Pediatr Dent 37: 233-243.

6. Espelid I, Cairns J, Askildsen JE, Qvist V, Gaarden T, et al. (2006) Preferences over dental restorative materials among young patients and dental professionals. Eur J Oral Sci 114: 15-21.

7. Randall RC (2002) Preformed metal crowns for primary and permanent molar teeth: review of the literature. Pediatr Dent 24: 489-500.
8. Zimmerman JA, Feigal RJ, Till MJ, Hodges JS (2009) Parental attitudes on restorative materials as factors influencing current use in pediatric dentistry. Pediatr Dent 31: 63-70.

9. Morley J (1999) The role of cosmetic dentistry in restoring a youthful appearance. J Am Dent Assoc 130: 1166-1172.

10. Kindelan SA, Day P, Nichol R, Willmott N, FayleSA (2008) UK National Clinical Guidelines in Peadiatric Dentistry: Stainless Steel Preformed Crowns for Primary Molars. IntJ of Peadiatr Dent 18: 20-28.

11. Seale NS (2002) The use of stainless steel crowns. Pediatr Dent 24: 501-505

12. Randall RC, Vrijhoef MM, Wilson NH (2000) Efficacy of preformed metal crowns vs. amalgam restorations in primary molars: a systematic review. J Am Dent Assoc 131: 337-343.

13. Yilmaz Y, Simsek S, Dalmis A, Gurbuz T, Kocogullari ME (2006) Evaluation of stainless steel crowns cemented with glass-ionomer and resin-modified glass-ionomer luting cements. Am J Dent 19: 106-110.

14. Yilmaz Y, Gurbuz T, Eyuboglu O, Belduz N (2008) The repair of preveneered posterior stainless steel crowns. Pediatr Dent 30: 429-435.

15. Tinschert J, Natt G, Mohrbotter N, Spiekermann H, Schulze KA (2007) Lifetime of alumina- and zirconia ceramics used for crown and bridge restorations. J Biomed Mater Res B Appl Biomater 80: 317-321.

16. Ez-Pedo Ceramic Crowns for Children. A Clinical Resource Guide to EZ-Pedo's Posterior Crown.

17. Christensen GJ (2012) Pediatric Crowns Are Growing Up. Clinicians Report 5.

18. Braun S, Hnat WP, Freudenthaler JW, Marcotte MR, Hönigle K, et al. (1996) A study of maximum bite force during growth and development. Angle Orthod 66: $261-264$

19. Xu W, Bronlund JE (2010) Understanding Food Texture Using Masticatory Robots. Mastication Robots 290: 207-236.

20. Townsend JA, Knoell P, Yu Q, Zhang JF, Wang Y, et al. (2014) In vitro fracture resistance of three commercially available zirconia crowns for primary molars. Pediatr Dent 36: 125-129.

21. Yucel MT, Yondem I, Aykent F, Eraslan O (2012) Influence of the supporting die structures on the fracture strength of all-ceramic materials. Clin Oral Investig 16: 1105-1110. 